\title{
MÉTODOS PARA SUPERAÇÃO DE DORMÊNCIA EM SEMENTES DE AZEVÉM
}

\author{
Fernanda da Motta Xavier ${ }^{1}$ \\ Paulo Eduardo Eberhardt ${ }^{2}$ \\ Bruna Bezerra $^{3}$ \\ Andréa Martins ${ }^{4}$ \\ Letícia Dias $^{5}$ \\ André Brunes ${ }^{6}$ \\ Ireni Carvalho ${ }^{7}$ \\ Géri Eduardo Meneghello8
}

Resumo: O azevém (Lolium multiflorum Lam.) é uma forrageira de ampla utilização na formação de pastagens. O objetivo do trabalho foi avaliar a temperatura e o período de exposição mais adequado para o pré-esfriamento em sementes de azevém para superação da dormência. As sementes foram submetidas a diferentes temperaturas $\left(2 ; 5\right.$ e $\left.10^{\circ} \mathrm{C}\right)$ e períodos de exposição $(24 ; 48 ; 72$ e 96h) e após transferidas para germinador à $20^{\circ} \mathrm{C}$. O delineamento experimental utilizado foi inteiramente casualizado com 4 repetições. Todos os tratamentos proporcionaram um incremento na germinação de no mínimo 20 pontos porcentuais, obtendo-se os melhores resultados a partir das combinações de temperaturas de $2 ; 5$ e $10^{\circ} \mathrm{C}$ e períodos de 72 e 96 horas.

Palavras-chave: Lolium multiflorum Lam; Pré-esfriamento; Dormência.

\footnotetext{
1 Agronomia/Universidade Federal de Pelotas, Brasil. E-mail: fehxavier@hotmail.com.

2 Agronomia/Universidade Federal de Pelotas, Brasil. E-mail: pauloeduardoeberhartd@yahoo.com.br.

${ }^{3}$ Agronomia/Universidade Federal de Pelotas, Brasil. E-mail: brunarosa-@hotmail.com.

${ }^{4}$ Agronomia/Universidade Federal de Pelotas, Brasil. E-mail: amartinsfv@hotmail.com.

5 Agronomia/Universidade Federal de Pelotas, Brasil. E-mail: leticiawinke@yahoo.com.br.

${ }^{6}$ Agronomia/Universidade Federal de Pelotas, Brasil. E-mail: andre.brunes@gmail.com.

${ }^{7}$ Agronomia/Universidade Federal de Pelotas, Brasil. E-mail: nicaleitzke@hotmail.com.

${ }^{8}$ Agronomia/Universidade Federal de Pelotas, Brasil. E-mail: gmeneghello@gmail.com.
} 